\title{
The Non-Existent Documentary Nor Fiction
}

\author{
Diana Martinez Muñoz \\ Universidad Nacional de Colombia, Colombia \\ Melissa de Raaf \\ Kunsthochschule für Medien Köln, Germany
}

\begin{abstract}
The status of reality in cinema has been questioned since the invention of the movie camera. Reality, facts, and staging, among other issues, are aspects that have to be addressed in the filmmaking process and categorization of a film. This paper analyses the divergence of reality and cinematic representation in documentary filmmaking, a so-called nonfictional practice intended to document reality. In this filmmaking process, the artist is looking to create a specific narrative around the topics addressed in the film. As Maya Deren states,
\end{abstract}

(...) reality is first filtered by the selectivity of individual interests and modified by prejudicial perception to become experience; as such it is combined with similar, contrasting or modifying experiences, both forgotten and remembered, to become assimilated into a conceptual image; this in turn is subject to the manipulations of the art instrument; and what finally emerges is a plastic image which is a reality in its own right.

The manipulation of the political and the treatment of reality in cinema is the undeniable freedom of the artist. Aesthetic composition can either show or deny facts and shape the storytelling in any direction. In a time where digital manipulation of the cinematic work increasingly subverts what is commonly understood as a representation of reality, the ethical aspect of filmmaking and the critical agency of the audience become all the more important. This paper proposes a move away from the categorization of films into genres and advances the urgency of finding innovative ways of thinking and experiencing cinematic works.

Keywords: Reality, Narrative, Perception, Documentary, Fiction.

\section{Introduction}

The status of reality in audiovisual media has been questioned since the invention of the camera. Although early theorists celebrated the photographic image for its apparent mimetic quality, let us recall that the early moving image experiments were often, in fact, staged endeavours. We have to call to mind the Lumière brothers, who placed their camera outside their factory to capture Workers Leaving the Lumière Factory (Lumière, 1895), staging their shots (hence, hardly any of the workers coming through the gate looked directly at the camera). It is widely known that Robert J. Flaherty constructed Nanook of the North (1922), thereby instigating an extensive discourse on authenticity, deception, and ethics in documentary filmmaking. And, most markedly, Jean Rouch and Edgar Morin pacing through Musée de l'homme in their film Chronique d'un été, concluding:

\begin{abstract}
It can all be summed up in two arguments. Either our characters are blamed for not being true enough (...) or they're being blamed for being too true. (...) What does that mean? We're reaching a stage when we question truth which is not everyday truth, we've gone beyond that. As soon as they're more sincere than in life, they're labelled either as actors or as exhibitionists. That's our basic problem. If the audience thinks these are actors or exhibitionists, our film's a failure. But I know and I feel that they're neither." (Chronicle of a Summer, 1961)
\end{abstract}

Therewith, classifying a film as either fiction or non-fiction is certainly not a straightforward procedure. Additionally, an essentialist stance on film is in itself an impossibility as the audiovisual medium is in constant flux. ${ }^{1}$ In recent times, the distinction between what is 'real' and what is 'fake' has undergone increasing scrutiny. Technologies such as CGI and 'deep fakes' blur the boundaries to an extent that the virtual itself has become an aspect of the real. This short exploration of the topic shows that the discussion shouldn't be about defining or categorising genres, as it is an impossibility in itself, but about creating the possibility for expression with audiovisual media beyond defined boundaries.

\section{Shifting the paradigm}

Consumers, viewers, or audiences nowadays immersed in audiovisual media are willing to learn, be entertained, and experience the world through the process of watching clips on all kinds of platforms from short form clips on, for example, IGTV, Tiktok, and YouTube, to longer and serialised formats on streaming services and news outlets-, not to mention in cinemas, currently restricted due to the pandemic, and the more traditional feature films that are still being produced. Spectators 'visit' different places, 'tour' cities, observe other cultures, gain awareness of global situations, listen to other languages, live other people's lives, wander through non-existent, unknown, or fantasy worlds, travel in time to ancient or future stories, etcetera. Audiovisual or time-based media has become a way to live immersed in the world; it creates a different way of perceiving realities external to one's own. Our collective knowledge or understanding of things is formed by the multiple perspectives that these media grant us. All of them are biased, polarized; they address the same topics but from a different point of view and provide different information, different 
visions, different voices, and different stories. Media consumers therefore have the agency of shaping their own perspective on the world, their own judgment and knowledge, through their own thought processes.

On the other hand, the film industry, with its producers, commissioning television editors, distributors, genre-specific film festivals, and cinemas with their own particular programming, continue to categorize audiovisual media. The main categories being (narrative) fiction and documentary and, if neither fits, experimental. This paper suggests that this is a problem²: the categorization of media into either fiction or documentary is a problematic way of breaking down audiovisuals; it influences viewers and tells them in advance how to understand the material. Instead, we argue that the artist should be free to express her or his perspectives and to dare to create different narratives, generate misunderstandings and debate, and inspire analytical thinking. This paper analyses the divergence of reality and cinematic representation in documentary filmmaking, a so-called non-fictional practice intended to document reality, proposes a move away from the categorization of films into genres (documentary, fiction, experimental, or others), and advances the urgency for innovative ways of thinking and experiencing cinematic works, as well as the screening and showing of uncategorized material to the public. We propose several outlooks avoiding classification of audiovisuals, all of which empower audiences to act individually and reflect upon the media and, at the same time, provide artists with the autonomy needed to develop new pieces that do not manipulate the filmmaking process in a moral and strategically commercial way.

To make a short parenthesis in the form of a disclaimer: in academic research, the study of the differences between fiction and non-fiction, realism, 'reality', and the real in film, as well as the philosophical quest for thinking in film, makes sense in that these works are part of a discourse (as is this paper). We, as filmmakers and teachers who support our students as they develop innovative film narratives and forms of experimentation, also challenge these borders, categories, and fault lines. A problem arises when students are forced to clearly establish the type of work they seek to produce in order to comply with academic procedures, fulfil industry requirements, apply for funding, or go into business. This situation frustrates and confuses students, who due to a lack of confidence in their work may finally decide to adapt their works to fit standardized formats and materials.

These films generally lack the expressiveness intended from the artists standpoint ${ }^{3}$. Artists, who must seek a balance between theory, philosophy, practice-based research, experimentation with media, and interdisciplinary collaborative work exploring other practices, often find that terminology and categorization fail to fall neatly into place, and this allows their artwork to provide a discourse with new material. And yet, artists, when looking for platforms for their work, find that films are marketed according to historically-grown categories that have failed to keep up with the works that are being produced and discover that their pieces may never reach an audience, becoming instead forgotten files stored on hard drives, stories that are never screened.

When addressing documentaries, and given the genre's links to the word "documentation", the issue of veracity pops up immediately; audiences are meant to accept the information conveyed as truthful facts, as data, and institutions, artists, producers, and the industry find themselves in the role of defenders of truth through media that limit the way images, sound, and storytelling are portrayed. This same assumption has led to an obsession with reality and the urge to 'get closer' to it, based on the generalized idea that the more specific our approach to things, the better our understanding and the fairer our perspective. We end up observing reality too closely and, as happens when we zoom in on a photographic image, we see nothing but pixels, no information is delivered, and the abstraction is confusing and jumbled because the material has been detached from its context. For a more objective view of something, distance must be maintained to ensure a broader and more general view of a topic; however, if the distance is too great, no clear position can be communicated and certain pieces might lack detail and prove completely superficial. As Hito Steyerl states, "the uncertainty principle of modern documentarism" (Steyerl, 1) strands us in a field of information by amplifying reality. But this uncertainty can consequently be seen as a creative opportunity if we accept the following statement: the audience should not take the representation of reality as an absolute fact or as an 'only truth'. Viewers should be allowed to engage in processes of doubt, questioning, or free thinking as a way of analysing or criticizing. If creators of cinematic media approach the viewer in a different way, then more risks can be taken, different narratives can be created, and reality can take alternative shapes.

Labelling media, or being forced to give them names, biases both the viewer and the artist by imposing an initial perspective and eliminating other ways of interpreting the material or approaching the filmmaking process. In order to deal with the 'uncertainty principle of modern documentarism' and engage in the debate regarding the veracity of the real-versus-the fictional (staged, scripted), more and more terms have been coined: docu-fiction, docudrama, cinematic nonfiction, and hybrid formats, to provide the audience with a supposed context and the artwork with a term under which it can be marketed. These terms attempt to define the subtle differences in artistic practices, defying the conflation of reality and truth, but should a filmmaker (or producer, TV channel, etc.) decide to not make use of them, scandals are inevitable. In March 2021, for example, the film Lovemobil, produced by a German TV channel and labelled a documentary, was outed as staged and therefore 'fake'. ${ }^{4}$ We won't go into all the details concerning this case, but a 
brief exploration of the media outpour it generated reveals that unclear communication and terminology was responsible for much of the controversy. Elke Lehrenkrauss mentioned in an interview that her intent was to use "dramatic or scenic narration" and that she communicated this in an exposé published during the development process. In hindsight, it can be said that broadcasters made no attempt to clarify whether the film was to be labelled an observational documentary, a docu-fiction with actors, or something else. The real question is whether this should have mattered at all. It is, however, important that the actors are not credited as actors in the film and the staged parts are not marked, thereby violating the ethics of documentary filmmaking, falling into the historic entrapments filmmakers such as Flaherty created, and fueling the contemporary discourse on post truth and the troubled (or speculative) real. On the other hand, claims that the sole responsibility for the 'misunderstanding' lies with the filmmaker, regardless of the supervisory role of editorial staff during the film's debut (who on their website labelled the film a 'reportage', proving that 'even among broadcasters the terminology is no longer very clear') reveal to what extent young filmmakers are subject to the balance of power inherent in financing and production structures, as well as historically-grown but vague terminology.

In fact, the question remains why we even need these types of labels, especially when the artworks themselves defy and challenge categorization. Or, as stated in Robert Green's article, "Die, Hybrid! Die!":

"Documentaries are hybrid monsters by their very nature; wild combinations of realities and fictions have undisputedly yielded some of the most inspired cinematic moments in movie history."

One example of an outstanding and hard-to-label film is US-based Italian filmmaker Roberto Minervini's Stop the Pounding Heart (2013). The film, which has all the marks of 'realist' or 'minimalist' cinema ${ }^{6}-\mathrm{a}$ (single) hand-held camera, location filming, the use of natural light, diegetic sound, and naturalistic acting or non-professional actors- employs both so-called documentary observation and dramatized elements. The film premiered at the Cannes Film Festival (in the fictional narrative feature category) and screened at Dok Leipzig, an annual documentary and animation festival. ${ }^{7}$ Yet, none of the aforementioned marks seem to do the film justice, other than subscribing to it within a certain cinematic tradition. This moving portrait and sensitive observation of evangelical, home-schooled Sara can be seen as a coming-of-age love story, an exploration of a young woman's inner life as she struggles with her faith. But it also 'parallels' her life, as Minervini puts it, and becomes therefore much more than either a documentary or a fictional narrative. The story arch is constructed, but also flows from inner logic; the footage of a (real) birth is followed by invoked moments, but the audience is at all times aware of what they are watching and never questions the veracity of the images conveying authenticity. As A.O. Scott accurately notes in The New York Times:

Stop the Pounding Heart transcends both the red state-blue state split and limited, didactic ideas of cinematic realism. Its scenes, quiet and undramatic, are nonetheless suffused with an almost lyrical intensity, and its sympathy is as limitless as its curiosity. ${ }^{8}$

Another example is Chris Marker's Junkopia (1981), an audiovisual labelled a documentary. In this film, garbage, transformed into strange objects that might be understood as art pieces, appears in the middle of something that might be the sea, a lake, or a pond; the location is not clear. The audiovisual piece presents what humans leave behind as junk and shows how this 'junk' became other objects, and how absurd it appears in the absence of humans. Indeed, this 'junk' could be seen as future garbage. There is no direct coherence or synchronization between image and sound. Although the sound makes the viewer think about things that are not present in the frame, there is no dialogue and images do not do any concrete storytelling. One's attention is drawn to information provided at the beginning of the film regarding the location's precise geographic coordinates, including an amplified version and accurate data on the location. This information, however, is completely useless to the general viewer and the audience decides what to do with it: ignore it, look it up on the internet, find it funny, or, in some cases, not even notice it. The documentary's experimental approach allows viewers the freedom to interpret the movie based on their own analytical thinking process, their own experience and/or judgment. The same video becomes different narratives, different perspectives, and even different topics. The work demonstrates how an audiovisual can be approached by the artist in a very free way, inviting multiple understandings and endowing both the creator and the spectator with the autonomy to pursue a variety of exploration processes.

The Drive and Listen website ${ }^{9}$ lets users select a city, 'get into' a car, and drive around the city. $\mathrm{He}$ or she can choose to listen to background noise or a local radio station, or both. The user experiences a drive through one of the world's many cities, but does not control navigation. The media is composed from YouTube videos and the website functions as an interactive form of watching videos of cities around the world. It could be interpreted as a collection of documentaries that allows for a certain kind of user interaction, or it could be seen as an expanded documentary in which people experience the world, or as a simple app and not an audiovisual at all, or even a fiction, despite its clear documentation of realities. The project reveals how audiovisual material, when combined with other tools such as the internet, websites, and user experience systems, generates different narratives that become a form of storytelling and a way of acknowledging topics. It might also be seen as a transformation of the filmmaking process, 
as an interdisciplinary work that takes advantage of other practices, or as a collaborative production by a variety of professionals fabricating outcomes that could benefit the evolution of the media industry. Allowing the artist to expand according to her or his own interests by discarding limiting guidelines. But as long as media continues to be categorized into rigid segments, the same traditional pieces will continue to be produced, the huge potential of interesting work will be wasted, and projects created with no regard for these rules will be rejected.

From the artist's standpoint, the need to fit into a specific category will limit the filmmaking process. Given that fiction and documentary are the two most recognizable categories, time-based media automatically acquires a responsibility that predisposes the thinking processes of both creators and viewers. At the same time, because of the 'aura' surrounding documentaries, some works seem to exclude certain audiences who see them as approachable only by intellectuals or people with specific knowledge. This conjecture creates discrimination and unfairly deprives audiences of an opportunity for critical thinking. Society has reached a point where viewers are desperate for new material, new experiences, and although traditional cinematic experiences will continue, artists should take advantage of technology, new tools, new mediums, or a combination of practices that allow spectators to create their own understanding of issues through these works. Radical filmmaking processes should be taken into account. During the Covid-19 pandemic, the number of spectators increased and customer's viewing times reached unprecedented heights ${ }^{10}$. Consumers began exploring different platforms, discovered new ways of watching movies, and began taking chances by watching different formats of moving images. This has brought about new possibilities for artistic creation, but also new responsibilities and challenges for both viewers and creators. Likewise, when film shoots became complicated due to biosafety restrictions and social distancing, directors were forced to find other ways of filmmaking, new sources to work with, and aesthetics began to change. As new issues become important, filmmakers are experimenting with new processes. Suddenly, the media has begun to discuss the same subjects in completely different ways and has discovered new ways of thinking about topics through documentation, manipulation, staging certain situations, mixing archived files with actual content, employing imagination, data, and real-time information. It is now difficult to ascertain whether a fiction is based on facts or whether documented facts can be trusted. Reality has become all possibilities at the same time and consumers should have the opportunity to experience this. Audiovisuals must consider the excitement of the current times and develop narratives accordingly.

One of the difficulties in producing alternative narratives, other media, or more radical approaches to audiovisuals is the insecurity an artist experiences when stating a completely different point of view or addressing issues in a way that society finds unacceptable. In this sense, in keeping with Ranciere's 'distribution of the sensible', an artist's approach to politics will differ depending on how he or she integrates and mediates with established social structures (Ranciere 2004, 13). When faced with resistance, fear, or restricted freedoms, all media behave equally; their impressions, views, and analyses of the same issues are the same and the same narratives are repeated over and over again. Instead of allowing creators to state a position, they are instead encouraged to do something meaningless. As Ranciere affirms in the same text:

This equality of indifference is the result of a poetic bias: the equality of all subject matter is the negation of any relationship of necessity between a determined form and a determined content. Yet what is this indifference, after all, if not the very equality of everything that comes to pass on a written page, available as it is to everyone's eye? This equality destroys all of the hierarchies of representation and also establishes a community of readers as a community without legitimacy, a community formed only by the random circulation of the written word. (Ranciere 2004, 14)

Although this quote describes written art, the same applies to the field of cinematic art. It could be said that consumers of time-based media are lulled into a comfort zone when information simply passes through their eyes and ears, without requiring a thinking process; the audience is slowly induced into a coma-like state that requires no autonomous thinking. Much like when Colin McGinn exclaims, "There is nothing better after a hard day of philosophical thinking and writing than a 'mindless' movie" (Mullarkey, 2009, $x)$. Nonetheless, this should be seen as a political possibility that favours the artist's radical standpoint and makes addressing the same issues from different perspectives a tool to create different approaches for both creators and viewers. Audiovisual works in search of innovative cinematic languages and new narratives, that question and reflect tropes and clichés or experiment with different types of media that force the viewer into critical thinking can be anything from difficult or hard to watch to captivating and entertaining --but certainly don't have to be "mindless".

Jay Rosenblatt's Human Remains (1998) is a good example of a facts-based audiovisual that makes the spectator doubt the information in the work and forces him or her to view a much-dissected topic dictators- in a new way. We have been exposed to a lot of information about them, have been taught to see them as monsters, and we forgot that their behaviours are similar to those of normal citizens in our societies. Their desires, tastes, cravings, whims, fears, and private longings -in other words, the mundane- are typical of every human being. This documentary focuses precisely on the aspects of dictators that remain after we rid ourselves of the usual and horrible 
preconceptions. We realize that they are humans who share the same habits and simple practices as the rest of us. The information portrayed is the outcome of the director's research and takes the form of a first-person narration combining different visual material and sound constructed entirely from scratch. The dialogues, which deliver truthful information, are voiced by narrators who fake the voices of real characters, employing the same pitch and the same performance. The sound of the archival material is composed and, in fact, only a few actions or movements are supported by sound. This creates an unreal ambience accompanied by strange tonalities that influence the look of what seems to be a traditional documentary. In this example, Rosenblatt is unclear regarding the information that is delivered; he allows the viewer a chance to reflect on the topic in another way. The spectator can take it as truth or fiction; what matters is the film's message: that dictators are also human beings and, as such, subject to the same mundanity.

\section{Conclusion}

Portraying, capturing and representing reality as we perceive it, as well as constructing imaginative realities, is as much a part of the filmmaking process as the perception of life itself, in which fantasy is part of the constructed reality around us. Constructing narratives is what we do. Perpetuating certain narratives, or particular storytelling structures, is what media outlets do. But, in order to meet the challenges of a changing world and do it justice, we need innovative narratives, new ways of seeing and perceiving, and critical thinking.

The fact that commissioning television editors, funding institutions, and, hence, producers defend the broad simplification of categories such as documentary and narrative fiction based on what they perceive as audiences' conventional viewing habits is most curious, as these institutions perpetuate these habits by producing -and sticking to- the traditional categorizing of audiovisual products. In fact, they refuse to accept that both documentary and fiction, or nonfiction and fiction, are almost impossible to define. At the very least, the borders separating them are blurred, hybrid, or even, possibly, non-existent. In the post-cinematic landscape, 'traditional' forms and formats, as well as genres, will soon be exceeded by media innovations, while the terminology lags behind. The field of expanded media fares better in this respect, in that it focuses much more on the medium than on the actual content, which is still in its experimentation and development stage. Often, the recourse is taken to label this type of audiovisual output as experimental, forcing these works onto another distribution circuit and rejecting artists interested in developing a variety of alternative narratives. But this is not our point. We believe that by simply not labelling time-based artwork, and by taking the audience seriously, there is a chance that new narratives and innovative cinematic languages will evolve and draw wider recognition. The filmmaking process should be opened to practices that facilitate and allow audiences access to all representations of realities aimed at sharing experiences, acknowledging emotions, and providing an understanding of content, taking advantage of all mediums, platforms, and changes in the moving image in general. If our approach to categorization changes, film schools and learning processes will focus on developing experimentation and innovation. The combination of diverse disciplines and the radical implementation of technology and tools will lead to more attractive content, an opportunity for both creators and consumers to think unconventionally, and an evolution in time-based media.

\section{Notes}

1 "(...) cinema's convergence was and is always asymptotic, not only on account of old media being perpetually supplanted by the emergence of new media, but also in virtue of the moving target at which its convergence aims" (Mullarkey, 2009, xv)

2 The same applies to the duration of movies, categorized as short or long format which need to fall within a certain minute margin (otherwise, as it is said, the movie will be difficult to be selected in festivals, distributed, programmed in cinemas).

${ }^{3}$ In this respect, art academies (such as the Academy of Media Arts Cologne (KHM)) provide less restrictive environments: the work begins with exploring, experimenting, and developing what the artist wants to convey and the form or media most relevant for the work in question. This might differ from film schools where students are trained mainly for the film industry.

${ }^{4}$ https://www.zeit.de/kultur/film/2021-03/lovemobil-dokumen tarfilm-prostitution-ndr-faelschung/komplettansicht, https:// blog.goethe.de/arthousefilm/archives/978-Public-broadcasterdistances-itself-from-the-doc-Lovemobil.html. Last access on $18 / 04 / 2021$.

$5 \quad$ https://www2.bfi.org.uk/news-opinion/sight-soundmagazine/comment/unfiction/die-hybrid-die. Last access on 18/04/2021.

${ }^{6}$ As used in Italian Neorealism, the work of Iranian filmmakers Abbas Kiarostami and Mohsen Makhmalbaf in the 1990s, and the so-called Romanian New Wave, etc.

${ }^{7}$ The film won the main prize -the 2013 Golden Dove International Competition Documentary Film award- at this festival. https://www.dok-leipzig.de/en/film/20131879/stoppounding-heart, Last access on 18/04/2021.

8 https://www.nytimes.com/2014/09/19/movies/stop-thepounding-heart-reveals-minervinis-texas.html. Last access on 18/04/2021.

${ }^{9}$ Erkam Seker, "Drive and Listen". https://driveandlisten. herokuapp.com/. Last access on 18/04/2021.

10 https://www.nielsen.com/us/en/insights/article/2020/covid19-tracking-the-impact-on-media-consumption/

\section{Bibliography}

Ranciere, Jacques. 2004. The Politics of Aesthetics, The Distribution of the Sensible. New York: Gabriel Rockhill.

Lyotard, Jean-Francois. 1984. The Postmodern Condition: A Report on Knowledge. Minneapolis: University of Minnesota Press.

Arato, Andrew., and Eike Gebhardt. 1978. The Essential Frankfurt School Reader. New York: Urizen Books.

Steyerl, Hyto. 2001. Documentary Uncertainty. Revisiones. http://www.re-visiones.net/anteriores/spip. php\%3Farticle37.html. Last access on 18/04/2021.

Erkam, Seker. "Drive and Listen". https://driveandlisten. herokuapp.com/. Last access on 18/04/2021. 
Mullarkey, John, Refractions of Reality, Philosophy and the Moving Image, New York:Palgrave Macmillan, 2009

The Nielsen Company. "Covid-19: Tracking the Impact on Media Consumption". https://www.nielsen.com/us/ en/insights/article/2020/covid-19-tracking-the-impact-onmedia-consumption/. Last access on 18/04/2021.

\section{Filmography}

Junkopia. (1981). Directed by Chris Marker. USA. Argos Films.

Human Remains. (1998). Directed by Jay Rosenblatt. USA. The Danish Film Institute Workshop.

Stop the Pounding Heart. (2013). Directed by Roberto Minervini, USA.

Chronicle of a Summer. (1961). Directed by Jean Rouch and Edgar Morin. The Criterion Collection. 